\title{
Risk of venous thromboembolism from use of oral contraceptives containing different progestogens and oestrogen doses: Danish cohort study, 2001-9
}

\author{
(a) $(1) \Theta$ OPEN ACCESS
}

\begin{abstract}
Øjvind Lidegaard professor of obstetrics and gynaecology ${ }^{1}$, Lars Hougaard Nielsen statistician ${ }^{1}$, Charlotte Wessel Skovlund data manager and scientific assistant ${ }^{1}$, Finn Egil Skjeldestad professor of clinical medicine ${ }^{2}$, Ellen Løkkegaard senior registrar in obstetrics and gynaecology ${ }^{3}$

${ }^{1}$ Gynaecological Clinic 4232, Rigshospitalet, University of Copenhagen, Denmark; ${ }^{2}$ Department of Obstetrics and Gynaecology, Institute of Clinical Medicine, University of Tromsø, Norway; ${ }^{3}$ Department of Obstetrics and Gynaecology, Hillerød Hospital, University of Copenhagen, Denmark
\end{abstract}

\begin{abstract}
Objective To assess the risk of venous thromboembolism from use of combined oral contraceptives according to progestogen type and oestrogen dose.

Design National historical registry based cohort study. Setting Four registries in Denmark.

Participants Non-pregnant Danish women aged 15-49 with no history of thrombotic disease and followed from January 2001 to December 2009.

Main outcome measures Relative and absolute risks of first time venous thromboembolism.

Results Within 8010290 women years of observation, 4307 first ever venous thromboembolic events were recorded and 4246 included, among which 2847 (67\%) events were confirmed as certain. Compared with non-users of hormonal contraception, the relative risk of confirmed venous thromboembolism in users of oral contraceptives containing 30-40 $\mu \mathrm{g}$ ethinylestradiol with levonorgestrel was 2.9 (95\% confidence interval 2.2 to 3.8 ), with desogestrel was 6.6 (5.6 to 7.8), with gestodene was 6.2 (5.6 to 7.0), and with drospirenone was 6.4 (5.4 to 7.5). With users of oral contraceptives with levonorgestrel as reference and after adjusting for length of use, the rate ratio of confirmed venous thromboembolism for users of oral contraceptives with desogestrel was 2.2 (1.7 to 3.0), with gestodene was 2.1 (1.6 to 2.8), and with drospirenone was 2.1 (1.6 to 2.8). The risk of confirmed venous
\end{abstract}

thromboembolism was not increased with use of progestogen only pills or hormone releasing intrauterine devices. If oral contraceptives with desogestrel, gestodene, or drospirenone are anticipated to increase the risk of venous thromboembolism sixfold and those with levonorgestrel threefold, and the absolute risk of venous thromboembolism in current users of the former group is on average 10 per 10000 women years, then 2000 women would need to shift from using oral contraceptives with desogestrel, gestodene, or drospirenone to those with levonorgestrel to prevent one event of venous thromboembolism in one year.

Conclusion After adjustment for length of use, users of oral contraceptives with desogestrel, gestodene, or drospirenone were at least at twice the risk of venous thromboembolism compared with users of oral contraceptives with levonorgestrel.

\section{Introduction}

The influence of specific types of combined oral contraceptives on the risk of thrombotic events remains the most important safety issue for these products. Several studies have investigated the relation between combined oral contraceptives and venous thromboembolism, ${ }^{1-21}$ including newer large scale studies. ${ }^{17-19}$ These new studies showed an increased risk of venous thromboembolism in current users of combined oral contraceptives and a decreasing risk by both time of use and decreasing oestrogen dose.

\section{Correspondence to: Ø Lidegaard Lidegaard@rh.regionh.dk}

Extra material supplied by the author (see http://www.bmj.com/content/343/bmj.d6423/suppl/DC1) International classification of diseases codes used in study Codes for excluded diagnoses

Appendix 1: allocation rules applied in analysis

Appendix 2: rate ratios of venous thromboembolism with use of oral contraceptives with $3-40 \mu \mathrm{g}$ ethinylestradiol; different exposure line formation Appendix 3: rate ratios of venous thromboembolism with use of oral contraceptives with 3-40 $\mu \mathrm{g}$ ethinylestradiol; three sub-periods and during 2001-9

Appendix 4: rate ratios of venous thromboembolism with use of oral contraceptives with 3-40 $\mu$ g ethinylestradiol; different user categories during 2001-9 
Results on the significance of the type of progestogen differed. Ten studies reported an increased relative risk of venous thromboembolism among users of oral contraceptives with desogestrel or gestodene compared with those containing levonorgestrel, ${ }^{1} 24-79131718$ a difference that was significant in eight of the studies, ${ }^{124-6131718}$ whereas a further three studies found no difference. ${ }^{8}{ }^{14} 19$ In addition, four studies reported a higher relative risk of venous thromboembolism among users of combined oral contraceptives with drospirenone compared with those containing levonorgestrel, ${ }^{17} 182021$ whereas two other studies reported no difference. ${ }^{14}{ }^{19}$ Consequently, the European Medicines Agency asked our study team to revisit the Danish registry data for additional analyses, with a focus on differences in risk of venous thromboembolism between users of oral contraceptives with drospirenone and those with levonorgestrel in the period after the launch of drospirenone in 2001.

We assessed the relative and absolute risk of first time venous thromboembolism for users of oral contraceptives with different progestogens, different doses of oestrogen, and according to certainty of the diagnosis of venous thromboembolism. We also assessed the risk of venous thromboembolism in users of progestogen only pills and hormone releasing intrauterine devices.

\section{Methods}

We carried out a nationwide historical cohort study of all Danish women aged 15-49 during 1995-2009. The study focused on the period after the launch of combined oral contraceptives containing drospirenone in 2001. Information on the 1.2 million women of reproductive age in Denmark was collected from four sources of data: Statistics of Denmark, the national registry of patients, the national cause of death registry, and the national registry of medicinal products.

\section{Statistics of Denmark: identification of women}

Statistics of Denmark keeps records of all Danish citizens. A unique personal identification number is given to each citizen at birth or immigration. This number is used in public registries, enabling reliable linkage of data between registries. From Statistics of Denmark we identified Danish women in the age category 15-49 from 1 January 1995 to 31 December 2009. We also obtained data on length of schooling, ongoing or finished education, vital status, and emigration. Women were censored at death or emigration.

\section{National registry of patients: end points}

The national registry of patients has collected discharge diagnoses from all public and private hospitals in Denmark since 1977. From 1994 the registry has used diagnoses as coded in the ICD-10 (international classification of diseases, 10th revision). The web extra lists the codes used in this study.

To include first events only we excluded women with any type of venous or arterial thrombotic event before the study period (1977-2000). We also excluded women with malignant gynaecological disease, cancer of abdominal organs or breast, and lung or haematological cancer before the study period or we censored them at the time of diagnosis if any of these diseases occurred during the study period.

Surgery - the national registry of patients also records surgical codes from public and private hospitals. We excluded women at baseline who had undergone bilateral oophorectomy, unilateral oophorectomy on two occasions, hysterectomy, or sterilisation, or we censored them at the time of surgery.
Pregnancy - from the national patient registry we identified pregnancy outcomes and gestational age at termination (see web extra). We censored a woman's experience during pregnancy, as calculated from conception and three months after delivery (one month for abortions and ectopic pregnancies), from study follow-up.

Coagulation disturbances - we also excluded women with a coagulation disorder the first time such a diagnosis was recorded in the national patient registry, including Leiden factor V heterozygote or homozygote, prothrombin 20210 heterozygote or homozygote, protein C insufficiency, protein S insufficiency, and anti-thrombin III insufficiency.

\section{National cause of death registry}

As only those women admitted to hospitals would have been recorded in the national registry of patients, we also checked the national cause of death registry for lethal events from venous thromboembolism (see web extra table) during the study period (updated to 2008).

\section{National registry of medicinal products: data on contraceptive usage}

Since 1 January 1994 the national registry of medicinal products has collected information about filled prescriptions, including oral contraceptives. From this database we obtained daily updated information on redeemed prescriptions of oral contraceptives from 1995 to 2009 . We categorised the products according to progestogen type, oestrogen dose, and length of use. Oral contraceptives with levonorgestrel and 30-40 $\mu \mathrm{g}$ ethinylestradiol were subcategorised as phasic preparations with 30-40 $\mu \mathrm{g}$ ethinylestradiol or combined pills with $30 \mu \mathrm{g}$ ethinylestradiol.

A stepwise analysis was undertaken, including successively each of the following usage categories: starting use, defined as use of combined oral contraceptives with no history of hormonal contraception before the first prescription; new use, defined as starting use after a pause of at least 12 weeks for any prescription of a hormonal contraceptive; restarted use, defined as oral contraceptive use after a pause of 4-11 weeks; and switched use, defined as use of one preparation of oral contraceptive followed by use of a different preparation, within a pause of less than four weeks.

\section{Duration of use}

We estimated the duration of new use from the prescribed defined daily doses calculated from the date of prescription until the end date of defined daily doses of the last redeemed prescription or date of a study event. The duration of restarted use was defined as the period from the date of restart until the end date of defined daily doses of the last filled prescription or the date of a study event. Duration of switched use was calculated as the sum of use before switch and current use on the new preparation, until end date of defined daily doses of the last filled prescription or date of a study event. Thus the same woman could have several episodes of new, restarted, and switched use.

To account for use before the start of the study (left censoring bias), we assessed the use of oral contraceptives before the study period back to 1995. In doing this we allocated continuous users of hormonal contraceptives to the relevant category for duration of use on 1 January 2001. 


\section{Rules for allocation of person time to usage groups}

We used four overall rules (see web extra for further details) to allocate products to each usage group:

Rule 1-a woman's time at risk for venous thromboembolism was allocated to the oral contraceptive preparation prescribed from the date it was redeemed until the end date calculated from defined daily doses. If no new prescription was redeemed by four weeks after this end date, then we changed the woman's usage status to previous user. However, if the woman got a new prescription for the same product within four weeks, we considered it continuous current use.

Rule 2-if a woman got a new prescription for the same product before the end date of the previous prescription, we summarised the prescribed defined daily doses as continuous current use.

Rule 3-if a woman cashed a new prescription for a different product before the end date of the previous prescription, we excluded the first four weeks after filling the new prescription in either oral contraceptive category, because it would be difficult to know which of the two products would account for venous thromboembolism. After four weeks we categorised such the woman as a switched user of the new preparation. In this case we estimated the duration of use from the first prescription of the previous preparation.

Rule 4-if a prescription ended and thereafter a woman redeemed a prescription for a new oral contraceptive after more than four weeks and less than 12 weeks, we estimated the episode of restarted use from the date when the new prescription was filled. The gap was considered as previous use.

\section{Confounding}

\section{Social class}

We used length of schooling and level of education as proxies for social class. Four strata were applied: women with elementary school education only (9-10 years of schooling), women with ongoing or completed high school education (2-3 years after elementary school), women with high school and ongoing or ended middle education (3-4 years after high school), and women with high school and ongoing or ended long education (5-6 years after high school). A fifth category included women lacking information on education, typically the youngest.

\section{Body mass index}

The type of oral contraceptive could be related to body mass index as a consequence of the secular increases in body mass index and use of recently launched combined oral contraceptives by time. We controlled for calendar year to deal with potential long term confounding by body mass index. In addition we carried out subanalyses for the periods 2001-5, 2006-May 2007, and June 2007-9. We chose these periods because of new data after 2005 and because of a "pill crisis" in Denmark in June 2007 after extensive media attention on one woman with venous thromboembolism who used oral contraceptives with drospirenone.

\section{Smoking}

Data on smoking were not available. Smoking is a weak risk factor for venous thromboembolism in young women. ${ }^{13} \mathrm{We}$ have no reason to believe in preferential prescribing of specific oral contraceptives among smokers. In Denmark the correlation between smoking and length of education is strong. Thus, controlling for years of schooling and length of education may have captured most confounding (if any) influenced by smoking.

\section{Ovarian stimulation drugs}

Women treated for infertility with ovarian stimulation drugs (Anatomical Therapeutic Chemical classification G03G) are anticipated to be at an increased risk for venous

thromboembolism. Therefore we censored these women at first such treatment.

\section{Recent surgery}

From the national register of patients we identified women with venous thromboembolism who had undergone major surgery in the four weeks before admission. Major surgery was defined as a length of stay after surgery of more than one day, or orthopaedic surgery on the legs. We carried out sensitivity analyses with and without these women excluded.

\section{Validity of the outcome diagnoses in the national register of patients}

All events of venous thromboembolism during 2001-9 were cross checked with the national registry of medicinal products for anticoagulation therapy (defined as therapy with vitamin $\mathrm{K}$ antagonists or heparin). We defined women who were given anticoagulation therapy for at least four weeks as having confirmed venous thromboembolism. Thus we were able to restrict analyses to confirmed events only.

Furthermore, we validated the hospital charts of 200 randomly selected women with venous thromboembolism. Two independent skilled clinicians evaluated each chart and categorised each case as confirmed if two of three conditions were fulfilled: clinical signs of venous thromboembolism; diagnostic confirmation by ultrasound, phlebography, computed tomography, or scintigraphy (in case of pulmonary embolism); and at least four weeks of anticoagulation therapy after the diagnosis. The evaluation was done without knowledge of registry data on usage of oral contraceptives.

\section{Statistical analysis}

Data were analysed by multiple Poisson regression in five year age groups. We further stratified the estimates according to length of current use into: less than three months, 3-12 months, more than 12 months to four years, and more than four years.

We calculated absolute as well as relative risk estimates. Non-users of all types of hormonal contraception (never users plus former users) were used as the reference group for the relative risk estimates. Rate ratios were also calculated for the different product types. We adjusted the relative risk estimates for age, calendar year, length of schooling and education, and eventually for length of oral contraceptive use.

Sensitivity analyses were done for both different steps in exposure line formation and according to different categories of oral contraceptive use. We calculated three estimates of exposure lines: raw exposure analyses, in which no gap filling or extension of four weeks was realised; gap corrected exposure lines, in which gaps of less than four weeks were filled and (as a consequence of filling out gaps) exposures were prolonged with four weeks; and switch corrected exposure lines, in which we excluded the first four weeks after switch.

Four successive analyses were carried out for the exposure categories of starting oral contraceptives, adding new use, restarted use, and, finally, switched use. 


\section{Results}

During 1995 to 20091732254 Danish women aged 15-49 were identified, corresponding to 17329718 women years of observation. The study period from January 2001 to December 2009 included 1436130 women and 9954925 observation years. Among these women 455421 (31.7\%) had never used hormonal contraception and 980709 (68.3\%) were ever users of some kind of hormonal contraception.

After exclusions and censoring owing to pregnancy ( $\mathrm{n}=403972$ or 486037 women years); ovarian stimulation ( $n=74823$ or 460454 women years); previous cardiovascular disease including venous thromboembolism $(n=31252$ or 135828 women years); cancer ( $\mathrm{n}=21080$ or 135828 women years); coagulation disturbances ( $\mathrm{n}=5122$ or 19258 women years); hysterectomy, bilateral oophorectomy, or sterilisation ( $\mathrm{n}=146$ 019 or 760449 women years); censoring after three years of using a hormone releasing intrauterine device $(n=48875$ or 164 270 women years); and one month exclusions at switch of oral contraceptive use ( $n=252968$ or 32598 women years), 1296 120 women were included in the statistical analysis, contributing 8010290 women years of observation, with 4307 first time venous thromboembolic events recorded.

The venous thromboembolic events were distributed, with 82 (1.9\%) women having cerebral venous thrombosis, 2738 (63.6\%) deep venous thrombosis only, $1130(26.2 \%)$ pulmonary embolism (with or without deep venous thrombosis), 55 (1.3\%) portal thrombosis, $15(0.4 \%)$ cava thrombosis, $4(0.1 \%)$ thrombosis of a kidney vein, and $283(6.6 \%)$ unspecified deep vein thrombosis.

Of the 4307 venous thromboembolic events, 61 occurred in women using hormonal contraceptives with so little exposure time and so few venous thromboembolic events that we did not calculate estimates.

The adjusted relative risk increased 6.8-fold from the youngest to the oldest women, and by $41 \%$ over the study period $(5.1 \%$ per year), and was reduced by $51 \%$ with increasing length of education (table $1 \Downarrow$ ).

\section{Relative risk according to progestogen type and oestrogen dose}

Table $2 \Downarrow$ shows the absolute and relative risks of venous thromboembolism in current users of combined oral contraceptives with different types of progestogens and varying doses of oestrogen. The incidence rate of venous thromboembolism in non-users of combined oral contraceptives was 3.7 per 10000 women years. Compared with non-users, the relative risk of venous thromboembolism in current users of oral contraceptives with levonorgestrel and $30 \mu \mathrm{g}$ ethinylestradiol was 2.19 (95\% confidence interval 1.74 to 2.75 ) and with levonorgestrel phasic 30-40 $\mu$ g ethinylestradiol was 2.28 (1.85 to 2.83 ). The relative risk of venous

thromboembolism in current users of oral contraceptives with $30 \mu \mathrm{g}$ ethinylestradiol combined with desogestrel was 4.21 (3.63 to 4.87 ), with gestodene was 4.23 (3.87 to 4.63 ), and with drospirenone was 4.47 (3.91 to 5.11). The corresponding estimates for oral contraceptives with the same progestogens but $20 \mu \mathrm{g}$ ethinylestradiol were 3.26 (2.88 to 3.69), 3.50 (3.09 to 3.97 ), and 4.84 (3.19 to 7.33 ). Progestogen only products conferred no increased risk of venous thromboembolism, whether taken as low dose norethisterone pills, as desogestrel only pills, or in the form of hormone releasing intrauterine devices.
The relative risk of venous thromboembolism from using oral contraceptives with norethisterone, levonorgestrel, desogestrel, or gestodene decreased with decreasing oestrogen dose, whereas no difference was apparent between oral contraceptives with drospirenone and either $30 \mu \mathrm{g}$ ethinylestradiol or $20 \mu \mathrm{g}$ ethinylestradiol. Oral contraceptives containing drospirenone and $20 \mu \mathrm{g}$ ethinylestradiol were launched in Denmark in 2006.

\section{Relative risk by validity of diagnosis}

The venous thromboembolic events were stratified into confirmed (anticoagulation therapy recorded in the national registry of medicinal products) and unconfirmed (table $3 \Downarrow$ ). Of the 4246 events diagnosed among non-users of hormonal contraception or among users of products included in this study, $2847(67.1 \%)$ were confirmed and 1399 (32.9\%) had no or less than four weeks' anticoagulation therapy recorded in the registry. The relative risks of venous thromboembolism were generally twofold to threefold higher in the confirmed group than the unconfirmed group. Thus in the confirmed group the relative risk of venous thrombolism with use of oral contraceptives with levonorgestrel increased to around 3 , and for oral contraceptives with desogestrel, gestodene, drospirenone, or cyproterone and $30 \mu \mathrm{g}$ ethinylestradiol increased to at least 6.

Progestogen only products had relative risk estimates below unity compared with non-users in both the confirmed and the unconfirmed groups.

The rate ratio between the estimates in the confirmed and unconfirmed groups was highest for oral contraceptives with desogestrel and lowest for those with norethisterone (table 3).

The proportion of confirmed events for specific oral contraceptives varied from $64 \%$ to $84 \%$, and ranged from $72 \%$ to $78 \%$ for those with levonorgestrel, norgestimate, gestodene, and drospirenone and from $76 \%$ to $84 \%$ for those with desogestrel.

Table $4 \Downarrow$ shows the rate ratio estimates between different product types. In the confirmed group, oral contraceptives with desogestrel, gestodene, or drospirenone conferred at least twice the risk of venous thromboembolism compared with oral contraceptives with levonorgestrel, and the rate ratio between oral contraceptives with drospirenone and those with desogestrel or gestodene was 1.01 ( 0.86 to 1.18 ). The corresponding rate ratios in the unconfirmed group were generally lower. The comparison between oral contraceptives with drospirenone and those with levonorgestrel was thus 1.78 (1.21 to 2.60 ), or $16 \%$ lower than the 2.12 (1.68 to 2.66) in the confirmed group. The rate ratio between these two product groups for all venous thromboembolic events was 2.00 (1.64 to 2.43), not far off the estimate in the confirmed group.

\section{Relative risk adjusted for differences in length of use}

To account for differences in the distribution of lengths of use between the groups, analyses were done in which the rate ratios with oral contraceptives containing levonorgestrel and $30 \mu \mathrm{g}$ ethinylestradiol as reference were adjusted for differences in length of use and restricted to confirmed events (table $5 \Downarrow$ ). The rate ratio estimates were slightly reduced for the newest products, reflecting a relatively higher proportion of short term users in these groups. The overall results, however, were unchanged, and the rate ratio between oral contraceptives with drospirenone compared with those containing levonorgestrel was still 2.09 (1.55 to 2.82 ). Table $6 \Downarrow$ displays detailed results 
according to length of use and specific combinations of progestogen types and oestrogen dose.

\section{Sensitivity analyses}

\section{Relative risk through different steps in exposure line formation}

In preliminary analyses, the influence of different steps in the exposure line formation was investigated. In the raw exposure lines no gap filling or prolongation of exposure was realised. The adjusted rate ratio between oral contraceptives with drospirenone and $30 \mu \mathrm{g}$ ethinylestradiol and those with levonorgestrel and 30-40 $\mu$ g ethinylestradiol was 2.2 (1.7 to 2.8 ), and between oral contraceptives with $30 \mu \mathrm{g}$ ethinylestradiol and drospirenone versus oral contraceptives with $30 \mu \mathrm{g}$ ethinylestradiol and desogestrel or gestodene the rate ratio was 1.1 (0.9 to 1.3$)$.

In the gap corrected dataset these rate ratio estimates were unchanged, as they were in the dataset for switch corrected exposure lines. For this reason the analyses were done with all allocation rules applied (see web appendix 2).

\section{Relative risk in different sub-periods}

Another exploratory step in the analysis was to assess rate ratio estimates in three sub-periods. A non-significant tendency was for lower rate ratios for oral contraceptives with drospirenone compared with those containing levonorgestrel in the last period, but for the period 2001-9 the adjusted rate ratio between oral contraceptives with drospirenone and $30 \mu \mathrm{g}$ ethinylestradiol compared with those containing levonorgestrel and 30-40 $\mu \mathrm{g}$ ethinylestradiol was 2.00 (1.64 to 2.43), and for the sub-period 2001-5 was 2.16 (1.65 to 2.83). Similar results were found when oral contraceptives with other progestogens were compared with those containing levonorgestrel (see web extra appendix 3 ). Consequently, subsequent analyses were done for the whole period 2001-9.

\section{Results for different exposure categories}

Sensitivity analyses were also done according to different user categories, including successively first starters only, then starters and new users, then including restarters, and finally including switchers. Starters had slightly higher rate ratios between users of oral contraceptives with drospirenone compared with those containing levonorgestrel of 2.69 (1.76 to 4.10) than estimates including the other categories, where the same rate ratios were between 1.96 (1.57 to 2.44) and 2.05 (1.56 to 2.70). See web extra appendix 4 for details.

\section{Different reference groups}

A third methodological issue was the oestrogen component in the levonorgestrel products used as reference. The rate ratio of venous thromboembolism between users of oral contraceptives with levonorgestrel and $30 \mu \mathrm{g}$ ethinylestradiol and with levonorgestrel and 30-40 $\mu \mathrm{g}$ ethinylestradiol including phasic products did not differ significantly in any of the sub-periods. About half of women years using oral contraceptives with levonorgestrel contained $30 \mu \mathrm{g}$ ethinylestradiol, the other half phasic products $30-40 \mu \mathrm{g}$ ethinylestradiol. For the period 2001-9, the rate ratio between oral contraceptives with drospirenone and $30 \mu \mathrm{g}$ ethinylestradiol and all levonorgestrel products with 30-40 $\mu \mathrm{g}$ ethinylestradiol was 2.00 (1.64 to 2.43 ) and with only levonorgestrel and $30 \mu \mathrm{g}$ ethinylestradiol was 2.04 (1.58 to 2.63). Accordingly, all users of oral contraceptives with levonorgestrel and $30 \mu \mathrm{g}$ or $30-40 \mu \mathrm{g}$ ethinylestradiol were chosen as reference group. For rate ratio comparisons with specifically drospirenone, however, estimates with both $30 \mu \mathrm{g}$ ethinylestradiol and all levonorgestrel users were calculated.

\section{Recent surgery}

Among women with confirmed venous thromboembolism, 33 (1.2\%) had major surgery in the four weeks before the admission for venous thromboembolism. The results were similar with and without exclusion of women with recent surgery. Thus the rate ratio between oral contraceptives with drospirenone and 30 $\mu \mathrm{g}$ ethinylestradiol compared with those containing levonorgestrel was 2.18 (1.62 to 2.94) with these events included and 2.13 (1.58 to 2.87 ) without.

\section{Chart evaluation of venous thromboembolism events}

Of 200 evaluated hospital charts, 148 (74\%) venous

thromboembolic events were confirmed and 52 unconfirmed. Except for two women with distal limb thrombosis who were not offered anticoagulation therapy, the remaining 146 confirmed events were in women who had received anticoagulation therapy. However, two unconfirmed events were in women who had received anticoagulation therapy; one for a recent venous thromboembolism, which was not excluded because it was coded at the primary admission (before actual admission) with a superficial venous thrombosis diagnosis and therefore not excluded as previous venous thromboembolism. The other woman was treated for connective tissue disease. All 200 evaluated patients coded as having venous thromboembolism had clinical symptoms at admission.

Of the 200 validated events, 148 (74.0\%) women had received anticoagulation therapy according to the medical charts. Of these, 133 (89.9\%) were recorded in the national registry of medicinal products as having had anticoagulation therapy, suggesting that about $10 \%$ received treatment for free from the hospitals, and therefore were not recorded in the registry.

Among the 52 women without information on anticoagulation therapy in the medical charts, four $(7.7 \%)$ were recorded in the registry as having received anticoagulation therapy. This can occur when treatment starts after discharge from the department to which the women were primarily admitted-that is, initiated from a coagulation laboratory just after discharge from the department. If these four events were added to the confirmed events in the sample of 200 women, the confirmed proportion increased to 152 of 200 , or $76.0 \%$.

\section{Discussion}

This study found that when compared with non-users of hormonal contraception, current users of oral contraceptives with levonorgestrel were at a threefold increased risk for confirmed venous thrombosis and users of oral contraceptives with desogestrel, gestodene, drospirenone, or cyproterone acetate a sixfold to sevenfold increased risk. This would give a rate ratio between the groups using oral contraceptives with desogestrel, gestodene, drospirenone, or cyproterone and those using oral contraceptives with levonorgestrel of at least 2 .

Before interpreting the results of this analysis, the main differences in study design and analysis between the present and the primary publication ${ }^{18}$ should be revisited. Potential biases in our primary publication were dealt with as follows: we eliminated left censoring bias by letting the new study period begin in 2001, with full exposure history for the previous six years; we defined length of use as duration of actual use rather 
than the sum of all periods of use; we used four strata for duration of use, instead of three, ensuring a more detailed length of use allocation within the first year; we excluded the first exposure month after a switch, because of uncertainty as to which product group a woman should be allocated in case of venous thromboembolism in this period; analyses were stratified into confirmed and unconfirmed venous thromboembolic events; and a more effective exclusion of predisposed women including women with coagulation disorders was effected.

\section{Results according to progestogen type and oestrogen dose}

The addition of four more study years from 2006-9 and the restriction of the analyses to the period after 1 January 2001 did not change the overall results of our primary publication covering 1995-2005. With the additional data we reconfirmed and substantiated a differential risk of venous thromboembolism between users of combined oral contraceptives with different progestogens and (although to a less extent) with different oestrogen doses.

According to the present analysis, with the same dose of oestrogen, combined oral contraceptives containing the progestogens desogestrel, gestodene, cyproterone, or drospirenone confer about the same relative risk of venous thromboembolism, a risk that is about twice that from use of combined oral contraceptives with the same dose of oestrogen and levonorgestrel. Phasic combined oral contraceptives with levonorgestrel may confer a slightly but not significantly higher risk of venous thromboembolism than oral contraceptives with levonorgestrel and $30 \mu \mathrm{g}$ ethinylestradiol, which could be due to the slightly higher total dose of oestrogen in the former group. Consequently the relative risk estimates are slightly smaller when the reference group was the whole group of oral contraceptives containing levonorgestrel than if compared with only oral contraceptives with levonorgestrel and $30 \mu \mathrm{g}$ ethinylestradiol.

The oral contraceptives with desogestrel or gestodene and 20 $\mu \mathrm{g}$ ethinylestradiol implied a relative risk of venous thromboembolism that were $23 \%$ and $17 \%$ lower than the same progestogens with $30 \mu \mathrm{g}$ ethinylestradiol. The missing trend for oral contraceptives with drospirenone according to oestrogen dose could be a consequence of fewer events $(n=23)$ in the group using $20 \mu \mathrm{g}$ ethinylestradiol, more active pill per cycle for one of the $20 \mu \mathrm{g}$ products, or could also be influenced by the introduction of these oral contraceptives in 2006, on the assumption that attention to adverse effects is highest for new products. However, the $70 \%$ confirmed venous thromboembolism events in the new low dose drospirenone group was close to the proportion of confirmed events for the older oral contraceptives with drospirenone and $30 \mu \mathrm{g}$ ethinylestradiol (74\%), which does not support differential attention by women or their doctors.

\section{Rate ratios and validity of diagnosis}

More than two thirds of the included venous thromboembolic events were confirmed by a record of anticoagulation therapy in the national registry of medicinal products. Importantly, some women have treatment for free (owing to local policies in some hospitals when handing out these drugs) and consequently are not recorded in the registry. According to our random analysis of medical charts, an additional $10 \%$ are women with real events of venous thromboembolism, receiving anticoagulation treatment for free from the hospitals. A further small percentage of women start treatment after discharge, bringing the real proportion of confirmed events up to 152 of 200 , or $76 \%$.

In a previous case-control study during 1994-8, we got information from departments that $3.6 \%$ of cases were unconfirmed. ${ }^{13}$ In addition, 95 of 1094 (8.7\%) women who responded could not confirm their diagnosis, leaving what we considered to be $87.7 \%$ of valid cases. The stricter validation in the subsample in this study resulted in $76 \%$ with a valid diagnosis. The difference of about $10 \%$ may be explained by women who have clinical symptoms of venous thromboembolism at admission that could not be confirmed by radiography or ultrasonography. Such women could be told that they might have had venous thromboembolism that dissolved spontaneously or was too small to be confirmed by the available diagnostic equipment, and therefore did not require treatment. As a result of the lack of a more appropriate diagnosis such women might, nevertheless, be coded as having venous thromboembolism.

Compared with non-users of combined oral contraceptives, the relative risk of venous thromboembolism among current users of combined oral contraceptives was twofold to fourfold higher for confirmed than unconfirmed venous thromboembolism (table 3). The rate ratio estimates between different product groups were less sensitive, but nevertheless decreased by about $25 \%$ from the confirmed to the unconfirmed group (table 4).

\section{Exposure line formation}

Estimation of rate ratios through different steps in exposure line formation was necessary for at least two reasons. Firstly, we decided on the analytical strategy before the analyses started. Secondly, the relative risk for users of specific products compared with non-users increased slightly (not significantly) through the different steps, indicating a successively higher validity of exposure allocation-for example, the relative risk estimate of oral contraceptives with levonorgestrel and $30 \mu \mathrm{g}$ ethinylestradiol increased from 1.9 (1.5 to 2.6$)$ to 2.1 (1.6 to 2.8) and for those with drospirenone from 4.4 (3.7 to 5.1) to 4.7 (4.0 to 5.4) through the different exposure lines.

Owing to the high consistency in the rate ratio estimates in the different exposure lines, it is unlikely that different rules or other time intervals in the allocation rules would have changed the rate ratios substantially.

\section{Analysis of different sub-periods}

Overall, the rate ratio estimates were stable throughout the study periods. The slightly lower rate ratio estimates after June 2007 compared with the previous period could be a consequence of the media event in June 2007. Shortly after this the Danish Society of Obstetrics and Gynaecology published a press release in which they stated that oral contraceptives with drospirenone were unlikely to confer a higher risk of venous thromboembolism than the prevailing third generation oral contraceptives with desogestrel or gestodene, but that oral contraceptives with levonorgestrel were likely to confer a lower risk. Consequently, women at an anticipated increased risk of venous thromboembolism were recommended progestogen only contraception or alternatively oral contraceptives with levonorgestrel as first choice.

Thereby some women at an anticipated increased risk of venous thromboembolism could have been prescribed products containing levonorgestrel, increasing the estimates for oral contraceptives with levonorgestrel and decreasing the estimates for those with drospirenone. However, the relative risk estimates for oral contraceptives with levonorgestrel and $30 \mu \mathrm{g}$ 
ethinylestradiol with non-users of hormonal contraception as reference did not change: 2.3 (1.7 to 3.1) during 2001-5 and 2.4 (1.6 to 3.6) from June 2007-9. In contrast, the estimates for oral contraceptives with drospirenone and $30 \mu \mathrm{g}$ ethinylestradiol decreased (non-significantly) from 4.7 (3.9 to 5.7) in 2001-5 to 4.1 (3.2 to 5.3) during 2007-9, which may explain the decreasing trend in the rate ratio estimates after June 2007.

\section{Recent surgery}

The exclusion of 33 women with confirmed venous thromboembolism who had major surgery within the previous four weeks did not change the results, primarily because of the low numbers. In addition, women undergoing surgery often receive anticoagulation therapy during their stay, and some may have stopped using oral contraceptives in the weeks around the surgery, circumstances for which we lacked information.

\section{Strengths and limitations of the study}

Expanding on our previous study by using four new years' worth of original data on exposure and end points confirmed our previously published results, ${ }^{18}$ and therefore increased the validity of the present results. The inclusion of all Danish non-pregnant women over a nine year period ensured a high external validity.

The information on exposure was complete and gathered for purposes other than a scientific analysis, eliminating the recall bias that is common in case-control studies, and the problems of continuous updating data on exposure in cohort studies. Furthermore, we eliminated the problem of left censoring by measuring use of combined oral contraceptives over a six year period before our study started. We obtained consistent results from sensitivity analyses on exposure line formation, different sub-periods, and according to different user categories (for example, starters, restarters).

Finally, we were able to validate venous thromboembolic events by linking individual data on diagnosis to succeeding anticoagulation therapy. Restricting the analysis to only confirmed events provided a quantitative assessment of the consequence of misclassification of some diagnoses on risk estimates.

This study does, however, have some limitations. We could not control for family disposition and body mass index. Adiposity is a well documented risk factor for venous thromboembolism. It is unlikely that there should be any important preferential prescribing of specific types of oral contraceptives to obese women before June 2007. After that time, however, the public recommendations to women at an anticipated increased risk of venous thromboembolism to choose a progestogen only contraception or oral contraceptives with levonorgestrel could have overestimated the risk for oral contraceptives with levonorgestrel and underestimated that for oral contraceptives with desogestrel, gestodene, or drospirenone. Some could argue that obese women are more likely to choose oral contraceptives with drospirenone. The empirical support for such selective prescribing is weak, however, and does not explain the high relative risk estimates for the other three oral contraceptives with desogestrel, gestodene, and cyproterone. To date, no study has shown any confounding influence from body mass index, as adjustment for body mass index in studies with this information did not change the rate ratio between oral contraceptives with different progestogens. ${ }^{14}{ }^{17-19}$ Therefore, preferential prescribing of oral contraceptives with third generation progestogens or drospirenone to obese women is unlikely to explain the doubled risk for these products compared with oral contraceptives containing levonorgestrel, especially after 2006.

The same argument applies to family disposition. Although an important risk factor, family disposition has not been found to be an important confounder in studies over the past 10 years.

About a quarter of our included venous thromboembolic events could not be confirmed by review of the medical records. This would underestimate the influence of combined oral contraceptives on the risk of venous thromboembolism, as shown by comparing the risk estimates for confirmed events in this study with those in our primary publication, ${ }^{18}$ whereas the rate ratio estimates were less sensitive to the inclusion of unconfirmed events.

The chart review confirmed a $99 \%$ positive predictive value of a diagnosis of venous thromboembolism with subsequent anticoagulation therapy, and that cross linkage with the national registry of medicinal products provided reliable validation of the events. However, we lost at least $10 \%$ of true events by excluding all events that were not recorded in the registry.

Table $7 \Downarrow$ summarises studies that specifically assessed the risk of venous thromboembolism from use of oral contraceptives with levonorgestrel, desogestrel, gestodene, or drospirenone. We excluded those studies that did not specify the compounds used or that lacked a reference group. Our new estimates for specific products restricted to confirmed events of venous thromboembolism are close to those in a Dutch study, ${ }^{17}$ whereas the rate ratio estimates between different product groups were slightly higher than in the Dutch study and slightly lower than in the two new studies from the United Kingdom ${ }^{20}$ and the United States. ${ }^{21}$ The UK and US studies included "idiopathic events" only, the risk estimates of which are expected to be slightly higher than those of studies that also include women with some other risk factors.

The two studies that did not find any difference in risk between oral contraceptives with drospirenone and those with levonorgestrel were two of the three studies that did not find any difference in risk between oral contraceptives with desogestrel or gestodene and those with levonorgestrel.

If we anticipate that oral contraceptives with desogestrel, gestodene, or drospirenone increase the risk of venous thromboembolism sixfold and that those with levonorgestrel increase the risk threefold, and that the absolute risk of venous thromboembolism in current users of the former group is on average 10 per 10000 women years, then 2000 women would need to shift from using oral contraceptives with desogestrel, gestodene, or drospirenone to those with levonorgestrel to prevent one event of venous thromboembolism in one year.

\section{Conclusion}

Compared with non-users of hormonal contraception, current users of oral contraceptives with levonorgestrel had a threefold increased risk of venous thromboembolism and those using oral contraceptives with desogestrel, gestodene, drospirenone, or cyproterone a six to sevenfold increased risk.

This would give a rate ratio between the groups using oral contraceptives with desogestrel, gestodene, drospirenone, or cyproterone and those using oral contraceptive with levonorgestrel of at least 2 . It is unlikely that these findings could be explained by bias or confounding.

We thank Torben Bjerregaard Larsen, expert in coagulation at Aalborg University Hospital, and Niels Tønder, cardiologist at Hillerød University Hospital, for their review of the 200 charts. 


\section{What is already known on this topic}

Studies have shown an increased risk of venous thrombosis (VTE) with use of combined oral contraceptives

The risk was higher with oral contraceptives containing the progestogens desogestrel and gestodene than those containing levonorgestrel Results on the risk from oral contraceptives with drospirenone have been conflicting

\section{What this study adds}

Women using oral contraceptives with drospirenone are at similar risk of VTE to those using oral contraceptives with desogestrel, gestodene, or cyproterone and higher than those using oral contraceptives with levonorgestrel

The risk of VTE was not reduced by using $20 \mu \mathrm{g}$ oestrogen instead of $30 \mu \mathrm{g}$ oestrogen in oral contraceptives with drospirenone To prevent one event of VTE in one year about 2000 women should shift from using oral contraceptives with desogestrel, gestodene, or drospirenone to those with levonorgestrel

Contributors: ØL, EL, and FES planned the study, supervised the analysis, and interpreted the results. $\varnothing \mathrm{L}$ wrote the manuscript. LHN did the statistical analyses and interpreted the results. CWS prepared the data from the national registry of patients and national death registry. All authors discussed and approved the final manuscript. $\varnothing \mathrm{L}$ is guarantor of the study. The sponsor had no influence on the design, performance, or interpretation of the results or on the manuscript.

Competing interests: All authors have completed the Unified Competing Interest form at www.icmje.org/coi_disclosure.pdf (available on request from the corresponding author) and declare that: Bayer Schering Pharma is thanked for covering the expenses of the analysis. All funding was given to Rigshospitalet, and the primary investigator received no salary for his work with this study, the EMA report or this manuscript. $\varnothing \mathrm{L}$ has within the last three years received honorariums for speeches on pharmacoepidemiological issues, including fees from Bayer Pharma Denmark and Novo Nordisk, and will be an expert witness for plaintiffs in a legal US case in 2011-2; FES received compensation for his work in the steering committee of the European Medicines Agency report.

Ethical approval: This study was approved by the Danish Data Protection Agency (Journal No 2010-41-4778). Ethical approval is not requested for registry based studies in Denmark.

Data sharing: No additional data available.

Bloemenkamp KWM, Rosendaal FR, Helmerhorst FM, Büller HR, Vandenbroucke JP. Enhancement by factor $V$ Leiden mutation of risk of deep-vein thrombosis associated with oral contraceptives containing a third-generation progestagen. Lancet 1995;346:1593-6.

2 Jick $\mathrm{H}$, Jick SS, Gurewich V, Myers MW, Vasilakis C. Risk of ideopathic cardiovascular death and nonfatal venous thromboembolism in women using oral contraceptives with differing progestagen components. Lancet 1995;346:1589-93.

3 World Health Organization Collaborative Study of Cardiovascular Disease and Steroid Hormone Contraception. Venous thromboembolic disease and combined oral contraceptives: results of international multicentre case-control study. Lancet 1995;346:1575-82.

4 World Health Organization Collaborative Study on Cardiovascular Disease and Steroid Hormone Contraception. Effect of different progestagens in low oestrogen oral contraceptives on venous thromboembolic disease. Lancet 1995;346:1582-8.

5 Spitzer WO, Lewis MA, Heinemann LAJ, Thorogood M, MacRae KD. Third generation oral contraceptives and risk of venous thromboembolic disorders: an international case-control study. BMJ 1996;312:83-8.

6 Farmer RDT, Lawrenson RA, Thompson CR, Kennedy JG, Hambleton IR. Population-based study of risk of venous thromboembolism associated with various oral contraceptives. Lancet 1997;349:83-8.
7 Bloemenkamp KWM, Rosendaal FR, Büller HR, Helmerhorst FM, Colly LP, Vandenbroucke JP. Risk of venous thrombosis with use of current low-dose oral contraceptives is not explained by diagnostic suspicion and referral bias. Arch Int Med 1999;159:65-70.

8 Lewis MA, MacRae KD, Kühl-Habich D, Bruppacher R, Heinemann LAJ, Spitzer WO. The differential risk of oral contraceptives: the impact of full exposure history. Hum Reprod 1999;14:1493-9.

9 Todd J-C, Lawrenson R, Farmer RDT, Williams TJ, Leydon GM. Venous thromboembolic disease and combined oral contraceptives: a re-analysis of the MediPlus database. Hum Reprod 1999;14:1500-5.

10 Jick H, Kaye JA, Vasilakis-Scaramozza C, Jick SS. Risk of venous thromboembolism among users of third generation oral contraceptives compared with users of oral contraceptives with levonorgestrel before and after 1995: cohort and case-control analysis. BMJ 2000;321:1190-5.

11 Parkin L, Skegg DCG, Wilson M, Herbison GP, Paul C. Oral contraceptives and fatal pulmonary embolism. Lancet 2000;355:2133-4.

12 Vasilakis-Scaramozza C, Jick H. Risk of venous thromboembolism with cyproterone and levonorgestrel contraceptives. Lancet 2001;358:1427-9.

13 Lidegaard Ø, Edström B, Kreiner S. Oral contraceptives and venous thromboembolism. A five-year national case-control study. Contraception 2002;65:187-96.

14 Dinger JC, Heinemann LAJ, Kühl-Habich D. The safety of a drospirenone-containing oral contraceptive: final results from the European Active Surveillance study on oral contraceptives based on 142,475 women years of observation. Contraception 2007;75:344-54

15 Jick SS, Kaye JA, Russmann S, Jick H. Risk of nonfatal venous thromboembolism in women using a contraceptive transdermal patch and oral contraceptives containing

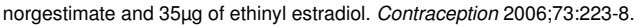

16 Pearce HM, Layton D, Wilton LV, Shakir SAW. Deep vein thrombosis and pulmonary embolism reported in the prescription event monitoring study of Yasmin. Br J Clin Pharm 2005;60:98-102.

17 Vlieg AVH, Helmerhorst FM, Vandenbroucke JP, Doggen CJ, Rosendaal FR. The venous thrombotic risk of oral contraceptives, effects of oestrogen dose and progestogen type: results of the MEGA case-control study. BMJ 2009;339:b2921.

18 Lidegaard Ø, Løkkegaard E, Svendsen AL, Agger C. Hormonal contraception and risk of venous thromboembolism: national follow-up study. BMJ 2009;339:b2890.

19 Dinger J, Assmann A, Möhner S, Minh TD. Risk of venous thromboembolism and the use of dienogest- and drospirenone-containing oral contraceptives: results from a German case-control study. J Fam Plann Reprod Health Care 2010;36:123-9.

20 Parkin L, Sharples K, Hernandez RK, Jick SS. Risk of venous thromboembolism in users of oral contraceptives containing drospirenone or levonorgestrel: nested case-control study based on UK General Practice Research Database. BMJ 2011:340:d2139.

21 Jick SS, Hernandez RK. Risk of non-fatal venous thromboembolism in women using oral contraceptives containing drospirenone compared with women using oral contraceptives containing levonorgestrel: case-control study using United States claims data. BMJ 2011;340:d2151

Accepted: 12 September 2011

\section{Cite this as: BMJ 2011;343:d6423}

This is an open-access article distributed under the terms of the Creative Commons Attribution Non-commercial License, which permits use, distribution, and reproduction in any medium, provided the original work is properly cited, the use is non commercial and is otherwise in compliance with the license. See: http://creativecommons.org/licenses/bync/2.0/ and http://creativecommons.org/licenses/by-nc/2.0/legalcode. 


\section{Tables}

Table 1/ Characteristics of current users and non-users of combined oral contraceptives and adjusted relative risk of venous thromboembolism according to age, calendar year, and length of education

\begin{tabular}{|c|c|c|c|c|c|c|c|c|}
\hline \multirow[b]{2}{*}{ Characteristics } & \multicolumn{3}{|c|}{ Current users } & \multicolumn{3}{|c|}{ Non-users } & \multirow[b]{2}{*}{$\begin{array}{l}\text { Adjusted rate ratio† } \\
\qquad(95 \% \mathrm{Cl})\end{array}$} & \multirow[b]{2}{*}{$P$ value } \\
\hline & Women years & $\begin{array}{c}\text { No of } \\
\text { events* }\end{array}$ & $\begin{array}{c}\text { Incidence per } \\
10000 \\
\text { exposure } \\
\text { years }\end{array}$ & Women years & $\begin{array}{c}\text { No of } \\
\text { events* }\end{array}$ & $\begin{array}{c}\text { Incidence per } \\
10000 \\
\text { exposure } \\
\text { years }\end{array}$ & & \\
\hline \multicolumn{9}{|l|}{ Age (years): } \\
\hline $15-19$ & 571333 & 239 & 4.2 & 670766 & 49 & 0.7 & 1 (reference) & - \\
\hline $20-24$ & 713623 & 343 & 4.8 & 346614 & 74 & 2.1 & $1.32(1.13$ to 1.54$)$ & $<0.001$ \\
\hline $25-29$ & 549862 & 375 & 6.8 & 463810 & 134 & 2.9 & 1.99 (1.66 to 2.38 ) & $<0.001$ \\
\hline $30-34$ & 430272 & 375 & 8.7 & 667937 & 211 & 3.2 & 2.91 (2.40 to 3.55 ) & $<0.001$ \\
\hline $35-39$ & 369859 & 447 & 12.1 & 861442 & 304 & 3.5 & 4.01 (3.31 to 4.87 ) & $<0.001$ \\
\hline $40-44$ & 261464 & 397 & 15.2 & 965951 & 467 & 4.8 & 5.29 (4.36 to 6.41$)$ & $<0.001$ \\
\hline $45-49$ & 153147 & 319 & 20.8 & 984209 & 573 & 5.8 & 6.58 (5.43 to 7.99$)$ & $<0.001$ \\
\hline \multicolumn{9}{|l|}{ Year: } \\
\hline 2001 & 335482 & 241 & 7.2 & 625168 & 175 & 2.8 & 0.71 (0.62 to 0.81$)$ & $<0.001$ \\
\hline 2002 & 339078 & 251 & 7.4 & 601282 & 198 & 3.3 & $0.76(0.66$ to 0.86$)$ & $<0.001$ \\
\hline 2003 & 340575 & 238 & 7.0 & 579767 & 174 & 3.0 & 0.70 (0.61 to 0.80$)$ & $<0.001$ \\
\hline 2004 & 342354 & 276 & 8.1 & 562409 & 205 & 3.6 & $0.81(0.72$ to 0.93$)$ & 0.002 \\
\hline 2005 & 341273 & 275 & 8.1 & 544028 & 217 & 4.0 & $0.86(0.76$ to 0.97$)$ & 0.02 \\
\hline 2006 & 339578 & 293 & 8.6 & 529811 & 205 & 3.9 & 0.87 (0.77 to 0.99$)$ & 0.03 \\
\hline 2007 & 337072 & 311 & 9.2 & 516775 & 245 & 4.7 & $1.01(0.90$ to 1.15$)$ & 0.82 \\
\hline 2008 & 336606 & 287 & 8.5 & 508635 & 190 & 3.7 & 0.90 (0.79 to 1.02$)$ & 0.10 \\
\hline 2009 & 337542 & 323 & 9.6 & 492855 & 203 & 4.1 & 1 (reference) & - \\
\hline \multicolumn{9}{|l|}{ Level of education: } \\
\hline $\begin{array}{l}\text { Elementary } \\
\text { schoolf }\end{array}$ & 695339 & 762 & 11.0 & 1194278 & 748 & 6.3 & 1 (reference) & - \\
\hline High school§ & 365466 & 275 & 7.5 & 505821 & 125 & 2.5 & 0.60 (0.54 to 0.67$)$ & $<0.001$ \\
\hline $\begin{array}{l}\text { High school and } \\
\text { middle education } \rrbracket\end{array}$ & 576803 & 673 & 11.7 & 1295503 & 518 & 4.0 & $0.68(0.63$ to 0.73$)$ & $<0.001$ \\
\hline $\begin{array}{l}\text { High school and } \\
\text { long education*** }\end{array}$ & 241662 & 223 & 9.2 & 909249 & 257 & 2.8 & 0.49 (0.44 to 0.55$)$ & $<0.001$ \\
\hline $\begin{array}{l}\text { No available } \\
\text { information }\end{array}$ & 1170290 & 562 & 4.8 & 1055878 & 164 & 1.6 & $0.78(0.68$ to 0.90$)$ & 0.0005 \\
\hline
\end{tabular}

*Events are venous thromboembolisms.

†Age estimates adjusted for year, level of education, and use of oral contraceptives; year estimates adjusted for age, level of education, and use of combined oral contraceptives; and education estimates adjusted for age, year, and use of combined oral contraceptives.

$\$ 9-10$ years of education.

§2-3 years of education after elementary school.

ๆ3-4 years of education after high school.

**5-6 years of education after high school. 
Table 2| Exposure time, number of events of venous thromboembolism, crude incidence per 10000 user years, and adjusted relative risk of venous thromboembolism in current users of different oral contraceptives and hormone releasing intrauterine device with non-users as reference group

\begin{tabular}{|c|c|c|c|c|}
\hline Group & Women years & No of events* & Crude incidence per 10000 user years* & Adjusted relative risk† $(95 \% \mathrm{Cl})$ \\
\hline Non-use & 4960730 & 1812 & 3.7 & 1 (reference) \\
\hline \multicolumn{5}{|l|}{ Progestogen with $50 \mu \mathrm{g}$ ethinylestradiol: } \\
\hline Norethisterone & 6848 & 11 & 16.1 & 5.66 (3.12 to 10.3$)$ \\
\hline Levonorgestrel & 23691 & 31 & 13.1 & 3.54 (2.48 to 5.05$)$ \\
\hline \multicolumn{5}{|l|}{ Progestogen with $30-40 \mu \mathrm{g}$ ethinylestradiol: } \\
\hline Norethisterone & 27355 & 10 & 3.7 & 1.57 (0.84 to 2.92$)$ \\
\hline Phasic levonorgestrel & 105970 & 89 & 8.4 & 2.28 (1.85 to 2.83$)$ \\
\hline Levonorgestrel combined & 104251 & 78 & 7.5 & 2.19 (1.74 to 2.75$)$ \\
\hline Norgestimate & 267664 & 165 & 6.2 & 2.56 (2.18 to 3.01$)$ \\
\hline Desogestrel & 170249 & 201 & 11.8 & 4.21 (3.63 to 4.87 ) \\
\hline Gestodene & 668355 & 738 & 11.0 & 4.23 (3.87 to 4.63$)$ \\
\hline Drospirenone & 286859 & 266 & 9.3 & 4.47 (3.91 to 5.11$)$ \\
\hline Cyproterone & 120934 & 109 & 9.0 & 4.10 (3.37 to 4.99$)$ \\
\hline \multicolumn{5}{|l|}{ Progestogen with $20 \mu \mathrm{g}$ ethinylestradiol: } \\
\hline Desogestrel & 470982 & 322 & 6.8 & 3.26 (2.88 to 3.69 ) \\
\hline Gestodene & 472118 & 321 & 6.8 & 3.50 (3.09 to 3.97$)$ \\
\hline Drospirenone & 23055 & 23 & 10.0 & 4.84 (3.19 to 7.33$)$ \\
\hline \multicolumn{5}{|l|}{ Progestogen only: } \\
\hline Norethisterone & 44168 & 9 & 2.0 & $0.56(0.29$ to 1.07$)$ \\
\hline Desogestrel & 29187 & 6 & 2.1 & 0.64 (0.29 to 1.42$)$ \\
\hline Levonorgestrel releasing intrauterine device & 155149 & 55 & 3.5 & 0.83 (0.63 to 1.08$)$ \\
\hline
\end{tabular}

${ }^{*}$ Events are venous thromboembolisms.

†Adjusted for age, year, and level of education. 
Table 3| Relative risk of venous thromboembolism among current users of oral contraceptives and hormone releasing intrauterine device according to certainty of diagnosis of venous thromboembolism, with non-users of hormonal contraception as reference group

\begin{tabular}{|c|c|c|c|c|c|c|}
\hline \multirow[b]{2}{*}{ Product type } & \multirow[b]{2}{*}{ Women years } & \multicolumn{2}{|c|}{ Anticoagulation (confirmed) } & \multicolumn{3}{|c|}{ Not recorded } \\
\hline & & No of events ${ }^{*}$ & $\begin{array}{c}\text { Adjusted relative risk } \dagger(95 \% \\
\mathrm{Cl})\end{array}$ & $\begin{array}{c}\text { No of } \\
\text { events* }\end{array}$ & $\begin{array}{c}\text { Adjusted relative risk } \dagger(95 \% \\
\mathrm{Cl})\end{array}$ & $\%$ confirmed \\
\hline Non-use & 4960730 & 1004 & 1 (reference) & 808 & 1 (reference) & 55.4 \\
\hline
\end{tabular}

Progestogen with $50 \mu \mathrm{g}$

ethinylestradiol:

\begin{tabular}{lcccccc}
\hline Norethisterone & 6848 & 7 & $6.24(2.95$ to 13.2$)$ & 4 & $5.10(1.90$ to 13.7$)$ & 63.6 \\
\hline Levonorgestrel & 23691 & 22 & $4.49(2.94$ to 6.85$)$ & 9 & $2.34(1.21$ to 4.52$)$ & 71.0 \\
\hline
\end{tabular}

Progestogen with $30-40 \mu \mathrm{g}$

ethinylestradiol:

\begin{tabular}{|c|c|c|c|c|c|c|}
\hline Norethisterone & 27355 & 8 & 2.24 (1.12 to 4.51$)$ & 2 & $0.73(0.18$ to 2.91$)$ & 80.0 \\
\hline Levonorgestrel phasic & 105970 & 66 & 3.09 (2.41 to 3.97$)$ & 23 & 1.31 (0.86 to 1.98$)$ & 74.2 \\
\hline Levonorgestrel combined & 104251 & 57 & 2.92 (2.23 to 3.81$)$ & 21 & 1.30 (0.84 to 2.00$)$ & 73.1 \\
\hline Norgestimate & 267664 & 119 & 3.52 (2.90 to 4.27$)$ & 46 & 1.44 (1.07 to 1.95$)$ & 72.1 \\
\hline Desogestrel & 170249 & 168 & 6.61 (5.60 to 7.80$)$ & 33 & 1.43 (1.01 to 2.04$)$ & 83.6 \\
\hline Gestodene & 668355 & 575 & 6.24 (5.61 to 6.95$)$ & 163 & $1.92(1.61$ to 2.28$)$ & 77.9 \\
\hline Drospirenone & 286859 & 196 & 6.37 (5.43 to 7.47 ) & 70 & 2.32 (1.80 to 2.98$)$ & 73.7 \\
\hline Cyproterone & 120934 & 88 & 6.35 (5.09 to7.93) & 21 & 1.58 (1.02 to 2.44$)$ & 80.7 \\
\hline
\end{tabular}

Progestogen with $20 \mu \mathrm{g}$

ethinylestradiol:

\begin{tabular}{|c|c|c|c|c|c|c|}
\hline Desogestrel & 470982 & 246 & 4.81 (4.15 to 5.56$)$ & 76 & $1.52(1.19$ to 1.94$)$ & 76.4 \\
\hline Gestodene & 472118 & 240 & 5.07 (4.37 to 5.88$)$ & 81 & $1.72(1.36$ to 2.19$)$ & 74.8 \\
\hline Drospirenone & 23055 & 16 & 6.95 (4.21 to 11.5$)$ & 7 & 2.58 (1.22 to 5.46$)$ & 69.6 \\
\hline \multicolumn{7}{|l|}{ Progestogen only: } \\
\hline Norethisterone & 44168 & 6 & $0.68(0.30$ to 1.51$)$ & 3 & $0.41(0.13$ to 1.28$)$ & 66.7 \\
\hline Desogestrel & 29187 & 3 & $0.61(0.20$ to 1.90$)$ & 3 & $0.63(0.20$ to 1.97$)$ & 50.0 \\
\hline $\begin{array}{l}\text { Levonorgestrel releasing } \\
\text { intrauterine device }\end{array}$ & 155149 & 26 & $0.72(0.49$ to 1.06$)$ & 29 & 0.95 (0.65 to 1.38$)$ & 47.3 \\
\hline
\end{tabular}

*Events are venous thromboembolisms.

†Adjusted for age, calendar year, and level of education. 
Table 4| Rate ratios of venous thromboembolism between users of combined oral contraceptives with different progestogens according to certainty of diagnosis of venous thromboembolism

Rate ratiof

Comparison groups

No of events* Partially adjusted Fully adjusted $(95 \% \mathrm{Cl}) \quad$ P value

Confirmed events

Drospirenone $+30 \mu \mathrm{g}$ EE versus:

\begin{tabular}{lcccc}
\hline Levonorgestrel $+30-40 \mu \mathrm{g}$ EE (all) & $196 v 123$ & 2.03 & $2.12(1.68$ to 2.66$)$ & $<0.001$ \\
\hline Levonorgestrel $+30 \mu \mathrm{g}$ EE (without phasic preparations) & $196 v 57$ & 2.08 & $2.18(1.62$ to 2.94$)$ & $<0.001$ \\
\hline Third generation progestogens $\S$ & $196 v 743$ & 0.98 & $1.01(0.86$ to 1.18$)$ & 0.9248 \\
\hline Desogestrel $+30 \mu \mathrm{g}$ EE $v$ levonorgestrel $+30-40 \mu \mathrm{g} \mathrm{EE}$ & $168 v 123$ & 2.18 & $2.20(1.74$ to 2.77$)$ & $<0.001$ \\
\hline Gestodene $+30 \mu \mathrm{g}$ EE $v$ levonorgestrel $+30-40 \mu \mathrm{g} \mathrm{EE}$ & $575 v 123$ & 2.04 & $2.07(1.70$ to 2.52$)$ & $<0.001$ \\
\hline
\end{tabular}

Non-confirmed events

Drospirenone $+30 \mu \mathrm{g}$ EE versus:

\begin{tabular}{lcccc}
\hline Levonorgestrel $+30-40 \mu \mathrm{g} \mathrm{EE}$ & $70 v 44$ & 1.71 & $1.78(1.21$ to 2.60$)$ & 0.0032 \\
\hline Levonorgestrel $+30 \mu \mathrm{g}$ EE (without phasic preparations) & $70 v 21$ & 1.70 & $1.78(1.09$ to 2.91$)$ & 0.0213 \\
\hline Third generation progestogens $\S$ & $70 v 196$ & 1.25 & $1.27(0.97$ to 1.68$)$ & 0.0840 \\
\hline Desogestrel $+30 \mu \mathrm{g}$ EE $v$ levonorgestrel $+30-40 \mu \mathrm{g} \mathrm{EE}$ & $33 v 44$ & 1.10 & $1.10(0.70$ to 1.73$)$ & 0.6764 \\
\hline Gestodene $+30 \mu \mathrm{g}$ EE $v$ levonorgestrel $+30-40 \mu \mathrm{g} \mathrm{EE}$ & $163 v 44$ & 1.45 & $1.47(1.05$ to 2.06$)$ & 0.0236 \\
\hline
\end{tabular}

$\mathrm{EE}=$ ethinylestradiol.

*Events are venous thromboembolisms.

†Adjusted for age and calendar year.

$\ddagger$ Adjusted for age, calendar year, and level of education.

$\S$ Desogestrel or gestodene. 
Table 5| Rate ratio of confirmed venous thromboembolism between different combined oral contraceptives with adjustment for length of use

\begin{tabular}{|c|c|c|c|c|}
\hline Product group & Women years & No of events* & Adjusted rate ratio† $(95 \% \mathrm{Cl})$ & $P$ value \\
\hline \multicolumn{5}{|c|}{ Progestogen with $30-40 \mu \mathrm{g}$ ethinylestradiol: } \\
\hline Norethisterone & 27355 & 8 & $0.76(0.36$ to 1.60$)$ & 0.47 \\
\hline Levonorgestrel phasic & 105970 & 66 & 1.07 (0.75 to 1.52$)$ & 0.71 \\
\hline Levonorgestrel combined & 104251 & 57 & 1 (reference) & - \\
\hline Norgestimate & 267664 & 119 & $1.18(0.86$ to 1.62$)$ & 0.30 \\
\hline Desogestrel & 170249 & 168 & 2.24 (1.65 to 3.02$)$ & $<0.001$ \\
\hline Gestodene & 668355 & 575 & 2.12 (1.61 to 2.78$)$ & $<0.001$ \\
\hline Drospirenone & 286859 & 196 & 2.09 (1.55 to 2.82$)$ & $<0.001$ \\
\hline Cyproterone & 120934 & 88 & 2.11 (1.51 to 2.95$)$ & $<0.001$ \\
\hline \multicolumn{5}{|c|}{ Progestogen with $20 \mu \mathrm{g}$ ethinylestradiol: } \\
\hline Desogestrel & 470982 & 246 & 1.60 (1.20 to 2.14$)$ & 0.0015 \\
\hline Gestodene & 472118 & 240 & 1.70 (1.27 to 2.27$)$ & 0.0004 \\
\hline Drospirenone & 23055 & 16 & 2.22 (1.27 to 3.89$)$ & 0.005 \\
\hline
\end{tabular}

*Events are venous thromboembolisms.

†Adjusted for age, calendar year, level of education, and length of use. 
Table 6 | Relative risk of venous thromboembolism in current users of combined oral contraceptives according to length of use and with non-users of hormonal contraception as reference

\begin{tabular}{|c|c|c|c|c|c|c|}
\hline \multirow[b]{2}{*}{ Product type } & \multirow[b]{2}{*}{ Women years } & \multirow[b]{2}{*}{ No of events* } & \multicolumn{4}{|c|}{ Adjusted relative risk $\dagger(95 \% \mathrm{Cl})$} \\
\hline & & & $<3$ months & 3-12 months & $>1-4$ years & $>4$ years \\
\hline Non-use & 4960730 & 1812 & 1 (reference) & 1 (reference) & 1 (reference) & 1 (reference) \\
\hline \multicolumn{7}{|c|}{ Progestogen with $30-40 \mu \mathrm{g}$ ethinylestradiol: } \\
\hline Levonorgestel (all) & 210221 & 167 & 4.07 (2.70 to 6.15$)$ & 2.54 (1.80 to 3.59$)$ & $2.12(1.61$ to 2.80$)$ & 1.88 (1.45 to 2.43$)$ \\
\hline Norgestimate & 267664 & 165 & 3.81 (2.60 to 5.58$)$ & $2.98(2.22$ to 4.00$)$ & $2.47(1.91$ to 3.20$)$ & $1.82(1.27$ to 2.59$)$ \\
\hline Desogestrel & 170249 & 201 & 4.59 (3.01 to 7.00$)$ & 4.20 (3.11 to 5.67$)$ & $3.77(2.95$ to 4.81$)$ & 4.64 (3.64 to 5.92$)$ \\
\hline Gestodene & 668355 & 738 & 4.83 (3.85 to 6.05$)$ & 4.65 (3.96 to 5.45$)$ & 4.12 (3.61 to 4.70$)$ & 3.94 (3.43 to 4.54$)$ \\
\hline Drospirenone & 286859 & 266 & 4.70 (3.45 to 6.40$)$ & 5.95 (4.88 to 7.24$)$ & 3.38 (2.69 to 4.24$)$ & 4.34 (3.10 to 6.08$)$ \\
\hline Cyproterone & 120934 & 109 & $4.23(2.50$ to 7.17$)$ & $4.21(2.95$ to 6.01$)$ & 4.90 (3.70 to 6.49$)$ & 2.43 (1.41 to 4.19$)$ \\
\hline \multicolumn{7}{|c|}{ Progestogen with $20 \mu \mathrm{g}$ ethinylestradiol: } \\
\hline Desogestrel & 470982 & 322 & 3.18 (2.31 to 4.38$)$ & 3.18 (2.55 to 3.98$)$ & 3.49 (2.91 to 4.17$)$ & 3.09 (2.42 to 3.96$)$ \\
\hline Gestodene & 472118 & 321 & $3.46(2.49$ to 4.81$)$ & 4.51 (3.69 to 5.52$)$ & $3.38(2.81$ to 4.06$)$ & $2.65(2.00$ to 3.51$)$ \\
\hline Drospirenone & 23055 & 23 & $6.16(2.76$ to 13.77$)$ & 7.25 (4.19 to 12.56$)$ & $2.58(0.96$ to 6.89$)$ & - \\
\hline
\end{tabular}

*Events are venous thromboembolisms.

†Adjusted for age, calendar year, and level of education. 
Table $7 \mid$ Relative risk of venous thromboembolism in current users of different combined oral contraceptives according to study. Non-users of hormonal contraception as reference group unless specified otherwise

Relative risk (95\% Cl)

Study Sampling period No of events* $\mathrm{COC}$ with levonorgestrel $\mathrm{COC}$ with third generation progestogenst COC with drospirenone

\begin{tabular}{|c|c|c|c|c|c|}
\hline Bloemenkamp ${ }^{1}$ & 1988-92 & 126 & 3.8 (1.7 to 8.4$)$ & 8.7 (3.9 to 19.3$)$ & NA \\
\hline $\mathrm{WHO}^{4}$ & 1989-93 & 433 & $3.6(2.5$ to 5.1$)$ & $7.4(4.2$ to 12.9$)$ & NA \\
\hline $\mathrm{Jick}^{2}$ & $1991-4$ & 80 & 1 (Reference) & 1.8 (1.0 to 3.2$)$ & NA \\
\hline Spitzer $^{5}$ & 1991-5 & 471 & 3.7 (2.2 to 6.2 ) & 6.7 (3.4 to 13 ) & NA \\
\hline Farmer $^{6}$ & 1991-5 & 85 & $3.1 \ddagger(2.1$ to 4.5$)$ & $5.0 \ddagger(3.7$ to 6.5$)$ & NA \\
\hline Lewis $^{8}$ & 1993-5 & 502 & 2.9 (1.9 to 4.2 ) & 2.3 (1.5 to 3.5 ) & NA \\
\hline Todd $^{9}$ & $1992-7$ & 99 & 1 (Reference) & 1.4 (0.7 to 2.8$)$ & NA \\
\hline Bloemenkamp ${ }^{7}$ & 1994-8 & 185 & 3.7 (1.9 to 7.2 ) & 5.6 (NA) & NA \\
\hline Lidegaard $^{13}$ & 1994-8 & 987 & 2.9 (2.2 to 3.8$)$ & 4.0 (3.2 to 4.9$)$ & NA \\
\hline Dinger $^{14}$ & $2000-4$ & 118 & 1 (Reference) & 1.3 (NS) & 1.0 (0.6 to 1.8$)$ \\
\hline Vlieg $^{17}$ & 1999-2004 & 1524 & 3.6 (2.9 to 4.6$)$ & $7.3(5.3$ to 10.0$)$ & 6.3 (2.9 to 13.7$)$ \\
\hline Lidegaard $^{18}$ & $1995-2005$ & 4213 & 2.0 (1.8 to 2.3 ) & 3.6 (3.3 to 3.8 ) & 4.0 (3.3 to 4.9$)$ \\
\hline Dinger $^{19}$ & 2002-8 & 680 & 1 (Reference) & NA & $1.0(0.6$ to 1.8$)$ \\
\hline Parkin $^{20}$ & $2002-9$ & 61 & 1 (Reference) & NA & 2.7 (1.5 to 4.7 ) \\
\hline $\mathrm{Jick}^{21}$ & $2002-8$ & 186 & 1 (Reference) & NA & 2.8 (2.1 to 3.8 ) \\
\hline \multicolumn{6}{|l|}{ Present study: } \\
\hline All reported events* & $2001-9$ & 4246 & 2.2 (1.7 to 2.8 ) & 4.2 (3.6 to 4.9 ) & 4.5 (3.9 to 5.1$)$ \\
\hline Confirmed events only* & $2001-9$ & 2707 & 2.9 (2.2 to 3.8$)$ & $6.8(5.7$ to 8.1$)$ & $6.3(5.4$ to 7.5$)$ \\
\hline
\end{tabular}

$\mathrm{COC}=$ combined oral contraceptives; $\mathrm{NA}=$ not available; $\mathrm{NS}=$ non-significant.

${ }^{*}$ Events are venous thromboembolisms.

†Desogestrel or gestodene.

$\ddagger$ Absolute risk per 10000 women years. 